University of Nebraska - Lincoln

DigitalCommons@University of Nebraska - Lincoln

\title{
$5-2020$
}

\section{Adjusting the lens of invasion biology to focus on the impacts of climate-driven range shifts}

Piper D. Wallingford

Toni Lyn Morelli

Jenica M. Allen

Evelyn M. Beaury

Dana M. Blumenthal

See next page for additional authors

Follow this and additional works at: https://digitalcommons.unl.edu/usgsstaffpub

Part of the Geology Commons, Oceanography and Atmospheric Sciences and Meteorology Commons, Other Earth Sciences Commons, and the Other Environmental Sciences Commons

This Article is brought to you for free and open access by the US Geological Survey at DigitalCommons@University of Nebraska - Lincoln. It has been accepted for inclusion in USGS Staff -- Published Research by an authorized administrator of DigitalCommons@University of Nebraska - Lincoln. 


\section{Authors}

Piper D. Wallingford, Toni Lyn Morelli, Jenica M. Allen, Evelyn M. Beaury, Dana M. Blumenthal, Bethany A. Bradley, Jeffrey S. Dukes, Regan Early, Emily J. Fusco, Deborah E. Goldberg, Inés Ibáñez, Brittany B. Laginhas, Montserrat Vilà, and Cascade J.B. Sorte 


\title{
Adjusting the lens of invasion biology to focus on the impacts of climate-driven range shifts
}

\author{
Piper D. Wallingford ${ }^{1,15}$, Toni Lyn Morelli ${ }^{2,3,4,15 \bowtie}$, Jenica M. Allen 2,5,6, Evelyn M. Beaury ${ }^{4}$, \\ Dana M. Blumenthal', Bethany A. Bradley ${ }^{3,4}$, Jeffrey S. Dukes ${ }^{80,9}$, Regan Early ${ }^{10}$, Emily J. Fusco (1) ${ }^{3}$, \\ Deborah E. Goldberg ${ }^{11}$, Inés Ibáñez ${ }^{12}{ }^{12}$, Brittany B. Laginhas ${ }^{4}$, Montserrat Vilà ${ }^{13,14}$ and \\ Cascade J. B. Sorte ${ }^{1}$
}

\begin{abstract}
As Earth's climate rapidly changes, species range shifts are considered key to species persistence. However, some range-shifting species will alter community structure and ecosystem processes. By adapting existing invasion risk assessment frameworks, we can identify characteristics shared with high-impact introductions and thus predict potential impacts. There are fundamental differences between introduced and range-shifting species, primarily shared evolutionary histories between range shifters and their new community. Nevertheless, impacts can occur via analogous mechanisms, such as wide dispersal, community disturbance and low biotic resistance. As ranges shift in response to climate change, we have an opportunity to develop plans to facilitate advantageous movements and limit those that are problematic.
\end{abstract}

A nthropogenic climate change is increasingly affecting species and ecosystems across the globe, threatening biodiversity at both local and broad scales ${ }^{1}$. In response, species from many taxonomic groups and ecosystems are undergoing redistribution towards higher latitudes and elevations due to both the direct (for example, physical limitations) and indirect (for example, altered species interactions) effects of climate change $e^{2-6}$. Because colonizing new habitats helps species persist both regionally and globally ${ }^{7,8}$, range shifts are seen as overwhelmingly beneficial to biodiversity conservation ${ }^{9}$. With the exception of some problematic species (for example, forest pests) ${ }^{10}$, as well as translocations and assisted migrations ${ }^{11-13}$, few studies (although see ref. ${ }^{3}$ for an example) have assessed the community and ecosystem impacts of species tracking their climate niche into new areas. This research gap remains despite theoretical literature that recognizes the potential for impacts and the need for such research ${ }^{14-17}$. The lack of studies on range shift impacts is surprising given that the introduction and spread of new species is often viewed by ecologists through the lens of invasion biology, where the primary concern is the potential for negative impacts on the recipient community. This dichotomy underscores the importance of considering the ecological impacts of range-shifting species in terms of both the benefits, particularly to their persistence, as well as the potential costs to recipient communities and ecosystem processes.

There are important ecological differences between introduced and range-shifting species (see Table 1 for definitions) that result in different levels of risk. For example, synthesis work considering a broad range of introduced species suggests that $10-50 \%$ become invasive and have negative impacts ${ }^{18-20}$. In contrast, results from analyses of range shift impacts are mixed, with some showing magnitudes of impacts similar to introduced species ${ }^{3}$ and others indicating that native species are less likely to be problematic when shifting to nearby recipient communities ${ }^{20}$. Potential differences in impact could be driven by range shifters' shared evolutionary history with some species in the recipient community; however, understanding which species are likely to have a large negative impact is critical for conservation of species in the many communities globally that are being joined by range shifters. Invasion ecology, therefore, provides insight for considering these interactions and assessing risk on a species-by-species basis.

The movement of populations in response to climate change is, in many ways, similar to the invasion of introduced species: it creates the potential for novel species interactions ${ }^{15}$. Both introduced and range-shifting species have been shown to impact recipient communities by consuming, parasitizing or competing with native species that lack the ability or defences to overcome them ${ }^{3,10}$. Nevertheless, range shifters frequently share an evolutionary history with some species in the recipient community, so interactions will not be completely novel, decreasing their potential for harmful impacts due to established niches and community roles ${ }^{21}$. As more species shift in response to climate change, methods for assessing potential impacts on recipient communities, and thus prioritizing which species to facilitate, become more valuable. Here, we leverage our understanding of biological invasions to describe a framework for assessing the likelihood and degree to which range shifters could impact recipient communities.

'Department of Ecology and Evolutionary Biology, University of California, Irvine, Irvine, CA, USA. ${ }^{2}$ Northeast Climate Adaptation Science Center, US Geological Survey, Amherst, MA, USA. ${ }^{3}$ Department of Environmental Conservation, University of Massachusetts, Amherst, MA, USA. ${ }^{4}$ Organismic and Evolutionary Biology, University of Massachusetts, Amherst, MA, USA. ${ }^{5}$ Department of Natural Resources and the Environment, University of New Hampshire, Durham, NH, USA. ${ }^{6}$ Miller Worley Center for the Environment, Mount Holyoke College, South Hadley, MA, USA. ${ }^{7}$ USDA Agricultural Research Service, Rangeland Resources \& Systems Research Unit, Fort Collins, CO, USA. ${ }^{8}$ Department of Forestry and Natural Resources, Purdue University, West Lafayette, IN, USA. ${ }^{9}$ Department of Biological Sciences, Purdue University, West Lafayette, IN, USA. ${ }^{10}$ Centre for Ecology and Conservation, Penryn Campus, University of Exeter, Cornwall, UK. "Department of Ecology and Evolutionary Biology, University of Michigan, Ann Arbor, MI, USA. ${ }^{2}$ School for Environment and Sustainability, University of Michigan, Ann Arbor, MI, USA. ${ }^{13}$ Estación Biológica de Doñana-Consejo Superior de Investigaciones Científicas (EBD-CSIC), Sevilla, Spain. ${ }^{14}$ Department of Plant Biology and Ecology, University of Sevilla, Sevilla, Spain. ${ }^{15}$ These authors contributed equally: Piper D. Wallingford, Toni Lyn Morelli. 凶e-mail: tmorelli@usgs.gov 


\begin{tabular}{|c|c|}
\hline $\begin{array}{l}\text { Range shifter or } \\
\text { range-shifting species }\end{array}$ & $\begin{array}{l}\text { A species tracking its environmental niche } \\
\text { through a range expansion or relocation beyond } \\
\text { its historical native range. }\end{array}$ \\
\hline Introduced species & $\begin{array}{l}\text { A non-native species transported to a new } \\
\text { ecosystem by humans, whether intentionally or } \\
\text { unintentionally. }\end{array}$ \\
\hline Invasive species & $\begin{array}{l}\text { An introduced species that causes negative } \\
\text { ecological, economic or environmental impacts. }\end{array}$ \\
\hline Recipient community & $\begin{array}{l}\text { The community into which an introduced or } \\
\text { range-shifting species arrives. }\end{array}$ \\
\hline Donor community & $\begin{array}{l}\text { The community from which an introduced or } \\
\text { range-shifting species originates. }\end{array}$ \\
\hline Establishment & $\begin{array}{l}\text { The process by which a founding population } \\
\text { increases in size and becomes self-sustaining. }\end{array}$ \\
\hline Spread & $\begin{array}{l}\text { The process by which a species' range expands } \\
\text { into new locations at an increasing distance from } \\
\text { the original area of establishment. }\end{array}$ \\
\hline
\end{tabular}

Assessing the impacts of climate-driven range shifts

Invasion ecologists have invested considerable effort in developing rubrics for predicting which introduced species are likely to become problematic ${ }^{22}$. Catford et al. ${ }^{23}$ proposed a holistic framework that broadly grouped these hypotheses into categories of propagule pressure, abiotic characteristics of the recipient community and biotic characteristics of both the recipient community and introduced species. Many (but not all) of the factors influencing invasion success, as identified in the Catford et al. framework, might also translate to impacts of range-shifting species. We can, therefore, use this framework to help assess the potential impacts of range shifters as well as to identify vulnerable recipient communities (Fig. 1).

Propagule pressure. Propagule or dispersal pressure is critical to the establishment of any introduced species ${ }^{24,25}$. Most invasive species experience a lag period between the initial introduction and the time at which they become invasive. This lag can last from $3-140$ years in plants and 10-38 years in birds ${ }^{26}$, and is attributed to a founder effect of the initial established population. Increased propagule pressure can reduce this lag time by increasing genetic diversity and adaptability of spreading populations ${ }^{27,28}$. Unlike with introduced species, for which genetic diversity is strongly limited by propagule pressure and number of introduction events, propagules of range shifters are likely to have been arriving sporadically into the recipient community at locations near the range margin. Thus, the existence of nearby source populations of range shifters could reduce time lags and increase the rate of population growth and range expansion, especially for species that are prolific propagule producers (Fig. 1) ${ }^{29}$. For example, marine organisms are expanding by an order of magnitude faster than terrestrial species, likely due to higher connectivity between communities, which translates to fewer barriers to widespread dispersal ${ }^{3}$. Higher propagule pressure at range margins makes it more likely that a range-shifting species will establish and spread into a novel recipient ecosystem.

Abiotic effects on impacts. Introduced species can establish in new communities when they have a competitive advantage or they occupy an empty niche; for example, anthropogenic disturbances can provide a window of opportunity for non-natives ${ }^{30}$. As the climate continues to change, recipient communities are likely to experience more frequent and acute abiotic stresses, which might lead to decreased population sizes and extirpations (even extinctions) in these communities ${ }^{4,31}$. This may enable the establishment of range shifters as they track their optimal climate conditions. For example, shorter winters and higher minimum temperatures are allowing many range-shifting insect pests (such as spruce and pine beetles) to colonize forests that were previously outside their ranges $^{32-34}$, leading to profound impacts on these ecosystems $s^{35}$. As these fast-growing insect pests shift into novel forest communities, drought conditions increase trees' vulnerability and exacerbate the pests' impacts $^{36,37}$.

Similarly, some of the most problematic introduced woody plant species host nitrogen-fixing microorganisms in their roots, thus allowing them to outcompete native species in an otherwise stressful, low-nutrient environment. Myrica faya in Hawaii, Lupinus arboreus in California grasslands and Acacia spp. in South Africa are examples of highly invasive shrubs and trees that benefit from greater access to nitrogen in nitrogen-poor soils ${ }^{38}$. Black locust (Robinia pseudoacacia) is a fast-growing, nitrogen-fixing native tree of southeastern North America that is currently undergoing a climate-mediated range shift ${ }^{39}$. As black locust moves north of its current range in response to climate change $e^{40}$, it is likely to have a competitive advantage over native vegetation, especially in nitrogen-deficient soils. Thus, recipient ecosystems that are heavily disturbed or have low nutrient availability may incur larger impacts from fast-growing and nitrogen-fixing range shifters.

Biotic characteristics. As with introductions, biotic characteristics of shifting species and recipient communities influence potential impacts (Fig. 1). Traits that make introduced species successful (for example, high fecundity, fast growth, generalist feeding habits, ability to engineer ecosystem conditions, and so on) will also facilitate the spread of range shifters ${ }^{41-46}$. Yet, because of the differences in shared evolutionary history with species in the recipient community, impacts on the recipient community are likely to differ ${ }^{47}$. Introduced species often benefit from interacting with new species (naïve prey) ${ }^{48}$ and leaving old enemies behind (enemy release) ${ }^{21}$. In contrast, species undergoing climate-induced range shifts settle in an adjacent community, which is likely to have some overlap of species composition and interactions with the donor community ${ }^{3,49}$. Such overlaps make it less likely that range shifters will leave enemies behind or encounter naïve prey, reducing the likelihood of novel impacts.

Yet there is evidence that range-shifting species can also experience enemy release ${ }^{50,51}$, especially when a range shift occurs over a long distance or crosses a biogeographic boundary that previously limited dispersal ${ }^{52}$. The probability that a range shifter will experience release from natural enemies and encounter naïve species in the recipient community is higher at ecotone edges, where dissimilar adjacent communities meet ${ }^{53}$. For example, the movement of tropical fish species to temperate communities has been facilitated by 'naïve' temperate algae with weaker chemical defences. In the southeastern Mediterranean Sea, the expansion of tropical herbivores led to a $60 \%$ loss in benthic biomass, a $40 \%$ decrease in species richness and, ultimately, a shift from a temperate reef system to one that more closely resembles adjacent tropical communities ${ }^{54}$. Such tropicalization of marine systems has become widespread as a result of range shifts ${ }^{55,56}$.

By applying an invasive ecology framework, we hypothesize that range shifters will be less likely to impact communities if some species have co-existed and interacted within the donor community. As with introduced species, the strongest impacts will likely be seen in recipient communities with high concentrations of specialist species ${ }^{57}$, populations with low genetic variability ${ }^{7}$, species that are already threatened by exploitation ${ }^{58}$ or species with low population $\operatorname{sizes}^{58}$. Communities with traits that confer high biotic resistance, such as high rates of predation, herbivory or strong competitive interactions ${ }^{59}$, will be most resistant to impacts of range shifters (Fig. 1) ${ }^{60}$. 


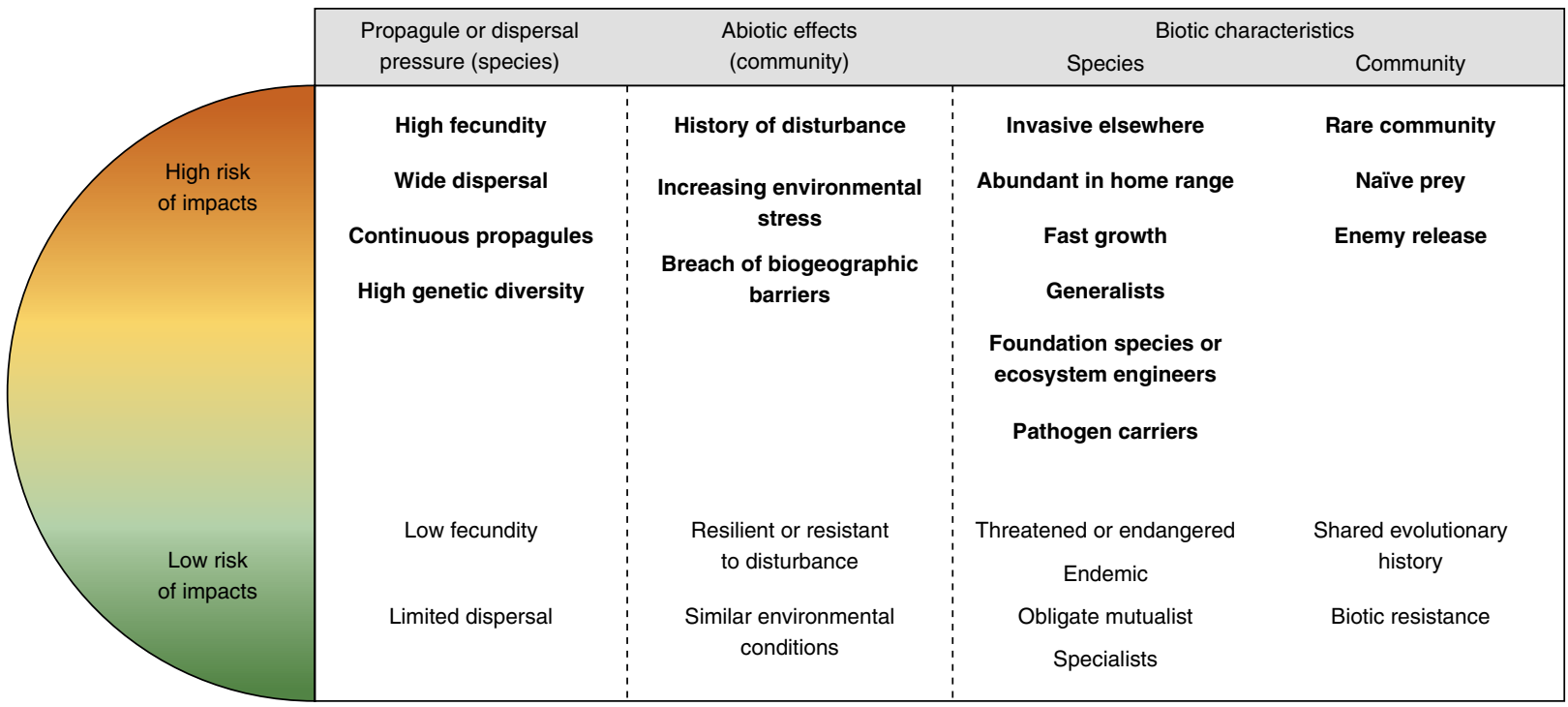

Fig. 1 | Risk assessments for biological introductions focus on the importance of three main components that lead to the successful establishment and spread of species: the introduction of propagules, the abiotic environment and biotic interactions. If characteristics that lead to negative impacts of introduced species on recipient communities (indicated in bold) are shared with species undergoing range shifts, there is greater risk (shown in orange) to recipient ecosystems from range shifters, which can inform management strategies.

\section{Impacts of range shifting can parallel introductions}

In contrast to introduced species, research on the effects of known range shifters has been relatively scarce despite several studies showing that the ecological and economic impacts can be equivalent ${ }^{61}$. In marine systems, for example, range-shifting and introduced species can cause community-level effects of the same direction and magnitude, but these impacts have been studied in fewer than $10 \%$ of documented marine range shifts ${ }^{3}$. Here, we present several examples that illustrate how impacts of range shifters could have been predicted by applying an invasive species risk assessment framework based on the traits and associated impacts reviewed above.

Range shifters benefit from novel interactions. Range shifters encountering new species can have significant impacts on recipient communities through changes to biotic processes, such as predation, competition and the transmission of new parasites or pathogens. In North American forests, the southern flying squirrel (Glaucomys sabrinus) is displacing the smaller northern flying squirrel (Glaucomys volans) as the southern species expands its range in response to increasing temperatures ${ }^{62}$. In addition to being superior competitors, southern flying squirrels are carriers of an intestinal parasite that is deadly to northern flying squirrels ${ }^{63,64}$. In the same forests, white-tailed deer and their associated parasites are expanding northward in response to climate change ${ }^{65}$. Due to the introduction of these parasites as well as increasing thermal stress, moose, boreal specialists, are ultimately predicted to be extirpated from sites along their southern range edge ${ }^{66}$. Conversely, moose are expanding at the northern end of their range in response to the encroachment of deciduous forest into the tundra, leading to a decline in native caribou populations ${ }^{67}$ (Fig. 2). In addition to highlighting the complexity of the impacts of climate change, these examples show how some range shifters will cause localized extirpations, similar to introduced species. Risk assessments can be used to identify range-shifting pathogen carriers and communities with vulnerable species or naïve prey before such impacts occur.

Invasive traits in range-shifting species. As with introduced species that become invasive, range shifters with certain traits are more likely to have negative impacts. For example, many shifting tree populations are composed of conifers, which often have biological traits that make them good colonizers. Most notably, many pine species have relatively high growth rates, are resistant to environmental stresses and develop monospecific stands that provide high propagule pressure $^{68}$.

Many invasive species that become dominant are also generalists, able to utilize a variety of different resources. In marine systems, ocean warming has allowed the long-spined sea urchin Centrostephanus rodgersii, previously limited by juvenile growth, to redistribute poleward from mainland Australia to Tasmania ${ }^{69}$. This urchin consumes a wide range of macroalgal species, leading to significant declines in kelp forest habitat ${ }^{70}$. Additionally, the long-spined urchin, a generalist herbivore, consumes many of the same prey species as the blacklip abalone (Haliotis rubra), a specialist. Reduction in resource availability has led to decreased abundance, fitness and survival among abalone populations ${ }^{71}$. As with introduced species, range shifters that are generalist consumers and possess 'weedy' traits are more likely to impact a recipient community.

Community changes by range shifters can scale up to alter ecosystems. The abundance, role and trophic level of a species in its donor community can be indicative of its success in a recipient community ${ }^{72,73}$. These effects on populations and communities can ultimately scale up to alter ecosystem states and processes. Ecosystem alterations can be observed as trees shift into new areas, leading to increases in aboveground and belowground biomass and shifts in nutrient cycling through litter decomposition ${ }^{6,74-76}$. Climate-related shifts of tree lines have been described in many parts of the world, and grasses are expanding in the tropics as fire frequency increases ${ }^{77}$. Yet the ecosystem impacts of these changes have been less explored than those that occur after invasions by introduced trees and grasses. Community and ecosystem effects have been observed in aquatic and marine systems as well. For example, herbivory by the long-spined sea urchin $C$. rodgersii has resulted in the collapse of kelp forests, leading to decreased biodiversity, a simplified food web and-at the ecosystem level-lower primary productivity ${ }^{78}$.

Another ecosystem shift occurring in tropical and subtropical regions is via the poleward expansion of mangroves into salt 


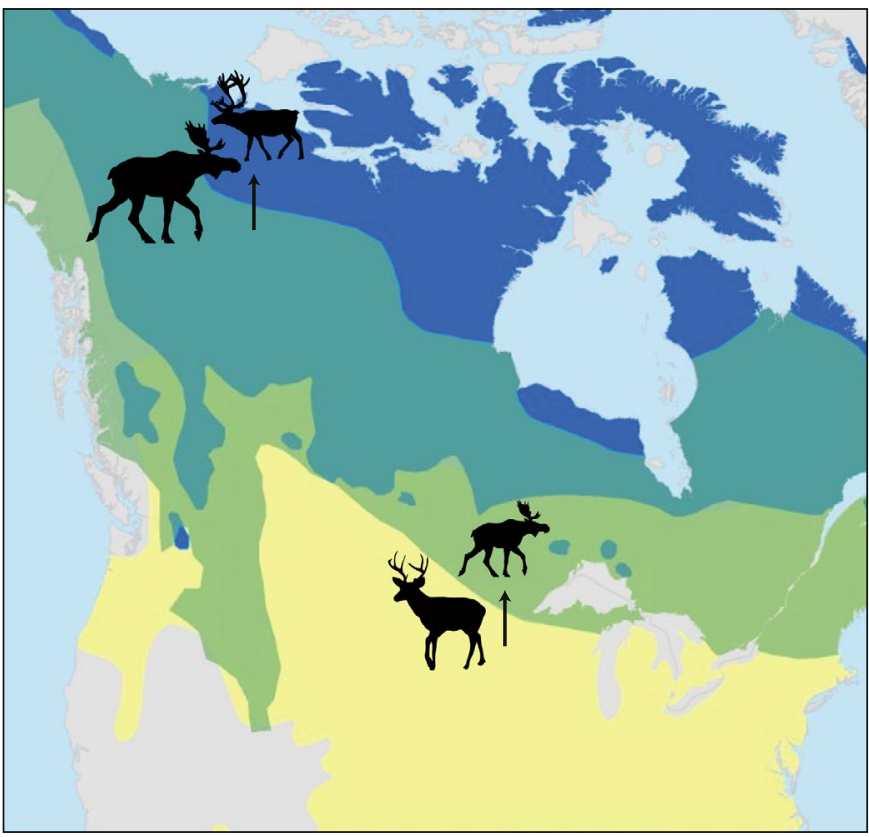

Fig. 2 | Range shifters can impact recipient communities. For example, as white-tailed deer expand their range (yellow) northward (arrows pointing upwards) in response to climate change, moose at the southern edge of their range (green) are experiencing greater rates of parasitism and are projected to undergo population declines ${ }^{66}$. In contrast, moose populations at the northern range edge are increasing and replacing caribou ${ }^{67}$ (blue). Smaller icons indicate range contractions. Ranges based on IUCN Red List of Threatened Species 2016 (refs. ${ }^{112-114}$ )

marshes ${ }^{79}$. In Florida, mangrove forests have doubled their area at the northern end of their historical range due to reduced frequency of cold-weather extremes ${ }^{80}$. Both mangrove trees and salt marsh grasses are foundation species in their respective ecosystems and play an important role in structuring communities by providing habitat and altering nutrient cycling ${ }^{80}$. Because mangroves have greater aboveground biomass and, therefore, structural complexity than native salt marsh vegetation, their expansion has broad implications for coastal wetland ecosystems. The establishment of introduced mangroves in sandflats has increased the concentration of fine sediments and organic matter, leading to a higher abundance and diversity of non-native macrofauna ${ }^{79}$.

The lack of defences of temperate species to tropical herbivores $^{81,82}$, general patterns of increased nutrient content with latitude $^{83}$ and increased disease due to increased herbivory ${ }^{84,85}$ might accelerate the tropicalization of these temperate wetland regions under future climate change. Previous research on the impacts of biological invasions on ecosystem properties and processes has shown that these impacts are highly context-dependent, as the magnitude and direction can vary both within and between types of impacts depending on taxa and ecosystems ${ }^{86}$. As with introductions, species that can alter the physical properties of the community (for example, ecosystem engineers) are most likely to have ecosystem-level impacts.

\section{Balancing conservation with risk}

Conservation options for promoting persistence (and preventing extinction) of species threatened by climate change include increasing habitat connectivity between communities to facilitate species movement and actively moving species-that is, assisted migration $^{11,12}$. In the context of assisted migration to facilitate climate change adaptation, conservation organizations, such as the
International Union for the Conservation of Nature (IUCN) ${ }^{87}$, are already considering invasion risk. However, increasing habitat connectivity to facilitate the movement of range-shifting species is generally considered an unmitigated good with little consideration of the full range of impacts on the recipient community.

Rather than placing a value on all species movements, we suggest using a risk-benefit analysis framework to assess potential impacts on a case-by-case basis. In some contexts, increasing habitat connectivity might best be based on analyses of donor and recipient communities with a focus on providing connectivity for low risk, nearby natives (Fig. 1). While there are inherent value judgements in assigning worth to species, we suggest that management should generally (1) facilitate range shifts that promote ecosystem services and biodiversity ${ }^{88}$ and (2) discourage range shifts of species with the potential to negatively impact sensitive or rare species and communities $^{89}$. In some cases, the analyses will be straightforward. For example, when range-shifting species are both locally and regionally uncommon, they could pose little risk to recipient communities (Fig. 1) and would benefit from opportunities to shift their ranges. This is unlikely to be true for species that have large impacts on their donor communities. Keystone predators (species with a disproportionate impact relative to their abundance) and foundation species (species that facilitate diversity by providing habitat and modifying their environment) might lead to management conundrums, as such species could pose great risk to recipient communities but also support the colonization of other range-shifting species with which they interact ${ }^{90}$.

Even range-shifting species with small impacts in their donor communities can have large impacts in recipient communities because of ecological surprises, such as novel interactions with species in the community ${ }^{91}$. A single invasion can be devastating to a community ${ }^{92}$, and risk assessments are a useful and often-applied tool for identifying species of concern. Therefore, like others who warn about the potential dangers of assisted migration ${ }^{93}$, we propose that, before facilitating range shifts, the ecological, economic and societal impacts associated with these management actions be considered ${ }^{88}$.

There are many assessment tools to evaluate the potential impacts of introduced species ${ }^{94}$. Notably, the Environmental Impact Classification for Alien Taxa (EICAT) framework is a standardized, objective and transparent approach adopted by the IUCN in 2016 that identifies the mechanisms through which introduced taxa can impact recipient communities ${ }^{73,87}$. Although this assessment was developed for introduced species, the mechanisms of impact outlined in EICAT apply to the interactions between range shifters and recipient communities as well. Identified mechanisms primarily fall into the biotic characteristics of the Catford et al. ${ }^{23}$ framework and consist of competition, herbivory and predation (including parasites and pathogens), hybridization, poisoning/toxicity, biofouling, ability to alter the ecosystem and interactions with other non-native species. These mechanisms are scored based on their magnitude of impact to the community, ranging from minimal (that is, negligible impacts, but no reductions in fitness for native species) to massive (that is, irreversible impacts through local, population or global extinctions; Fig. 3).

We suggest applying EICAT to rank and prioritize range-shifting species based on their potential impacts on recipient communities and to develop monitoring or control plans to limit those impacts. For example, communities receiving range-shifting species with the lowest potential to experience impacts (minimal and minor) are likely to benefit most from passive management actions, such as monitoring. Such range shifts could maintain or even increase community diversity and allow for persistence of populations under increasingly stressful environmental conditions. Although minor and moderate impacts lead to reductions of fitness in individuals or declines in population abundances, respectively, the 


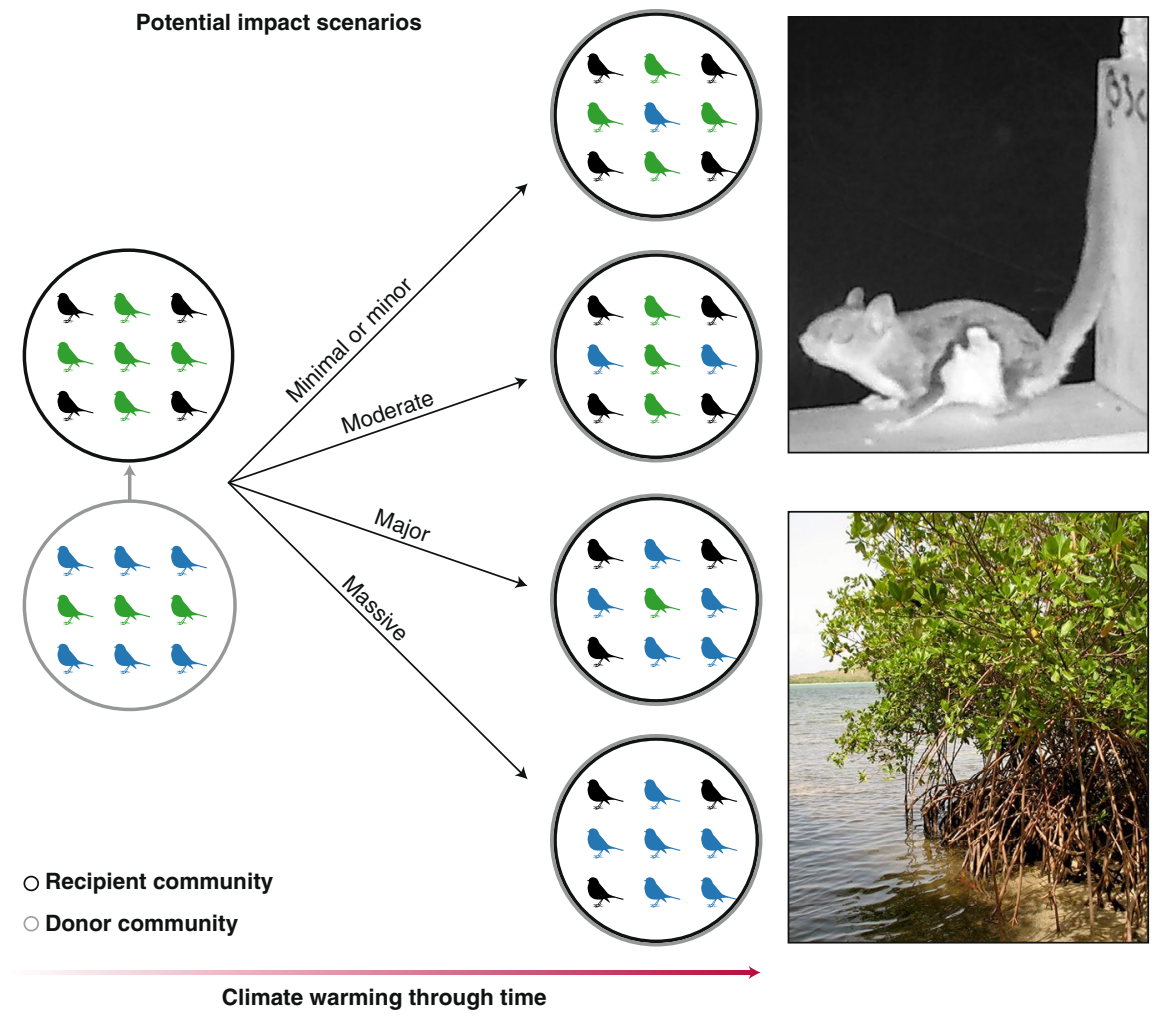

Fig. 3 | As climate change alters environmental conditions, range shifts can lead to new species interactions and changes to community structures depending on the magnitude of associated impacts. For example, as individuals from a nearby donor community (blue birds in grey circle) shift into a novel recipient community (green and black birds in black circle) in response to climate change, they might have minimal or minor impacts (few blue birds in a community of primarily green and black birds) up to major or massive impacts where the shifting species predominates. This range of impacts can be seen in the examples discussed here, including cases of southern flying squirrels displacing northern flying squirrels (moderate due to effects on populations) to tropicalization (massive, irreversible shifts in ecosystems). Photographs courtesy of Alexej Sirén and the U.S. National Park Service.

recipient community structure and functioning are preserved. Future communities might not be analogous to existing recipient communities, but shifts are likely to have a net positive impact on global biodiversity.

Species with major or massive impacts, however, might need to be actively managed through facilitating or restricting movement, as their impacts could alter community structure and composition and cause local extinctions in the recipient community. While such changes, by definition within the EICAT framework, are reversible for species with major impacts, those with massive impacts are likely to cause irreversible changes as the community passes a threshold from which it can no longer recover. In the cases of species with major or massive impacts, serious consideration should be given to whether the benefits of promoting the persistence of the range-shifting species or populations justify the impacts on the recipient communities. Based on approaches traditionally used to manage invasive species, we suggest the following specific strategies for range shifters:

- Involve stakeholders early: work closely with natural resource managers, conservation practitioners and decision-makers at every step of the process, including to identify priority ecological and cultural species ${ }^{95,96}$ and important ecological services associated with both range shifters and recipient communities.

- Identify management priorities for range-shifting species and recipient communities: what is the conservation status of the species? How important is the range shift for its persistence? How unique is the recipient ecosystem? How important are its constituent species and associated services for stakeholders? Supporting range shifts for species of conservation concern will remain a key climate change adaptation tactic for conservation practitioners and natural resource managers.

- Incorporate species distribution model forecasts: use the best available data and models to anticipate the movement of range shifters and identify high priority conservation areas, hotspots of biodiversity ${ }^{97}$ and hotspots of high impacts ${ }^{98,99}$. Additionally, triaging which species are most likely to persist under projected climatic conditions can inform where resources can be most effectively allocated. Regularly revise management proposals to incorporate updates to these forecasts.

- Use tools to assess invasion risk: consider the parallels between traits common in successful introduced invasives ${ }^{22}$ (Fig. 1) and their potential impacts $\left(\mathrm{EICAT}^{73}\right.$ ) to identify high- and low-risk range-shifting species.

- Monitor changes in recipient communities: monitor for shifts in abundance of target species and the arrival of new species, especially following disturbance and extreme climatic events ${ }^{24}$.

\section{Challenges and potential limitations}

Important knowledge gaps related to range-shifting species must be addressed to better understand the impacts that these species might have while also promoting persistence of species as their climate zones move. While range shifts have been documented for hundreds of species across taxa and ecosystems $\mathrm{s}^{3-5}$, they can be difficult to detect, as the historical ranges for many species are 
unknown or imprecise and our understanding of a 'native range' is not well-defined ${ }^{100}$. This is especially true for systems that are not as well-studied, such as deep-water marine systems that are difficult to access, and incorporating different spatial or temporal scales could further alter our definition of what constitutes a range-shifting species.

The impacts of range shifters, which might accrue more slowly than impacts of introduced species, have received less attention than invasion impacts; thus, our ability to predict future outcomes is limited. Range-shifting species could potentially undergo hybridization, experience toxicity, or evolve or adapt; an increased understanding of potential interactions in new environments is needed to evaluate these possible outcomes. Additionally, effects may differ across scales. Addressing these knowledge gaps will require working across broad stakeholder groups to leverage and continue existing monitoring programs and incorporate diverse resources, such as local and traditional ecological knowledge ${ }^{101}$.

Predicting potential shifts is further complicated by our limited understanding of the abiotic and biotic limits to species' ranges. Predicting which species are likely to undergo shifts requires a knowledge of organismal physiology and thermal limits and how these contribute to ability to disperse as well as to adapt in place. Additionally, while temperature is a primary driver of distribution patterns ${ }^{102,103}$, biotic resistance also plays a critical role ${ }^{49}$. Yet biotic interactions are, themselves, often altered by abiotic conditions ${ }^{16,104}$. Traits can act synergistically (for example, a drought causes reduced propagules), creating feedbacks that alter the magnitude of impacts. To detect species interactions and community impacts, manipulative in situ experiments are likely a necessary and important focus for climate change researchers. However, these experiments can be time-consuming or expensive, and a lack of experimental studies does not preclude using general risk assessment frameworks (Fig. 1) and knowledge from invasion biology to inform decision making. Additionally, risk assessments that are continually updated as new empirical data accrue can be used by practitioners, providing an accessible resource for those making management decisions.

Finally, we must acknowledge that anthropogenic climate change has led to unprecedented disruptions to global environments at a level rarely experienced before the Anthropocene ${ }^{105,106}$. Many species' ranges have already been dramatically altered by human impacts, which raises questions about how to classify species that expand into their historical habitat following extirpation and which incarnation of a community should be protected ${ }^{107,108}$. The rapid rate of anthropogenic climate change is likely to outpace species' ability to adapt. Range shifts, therefore, have been viewed as an alternative means to promoting global biodiversity. Yet, the potential feedbacks and consequences need to be considered as conservation goals may conflict with one another depending on the individual case. For example, mangroves and salt marshes provide similar ecosystem services. However, salt marsh systems have experienced significant area loss ${ }^{109}$, and range-shifting mangroves could further impact these vulnerable communities, highlighting the important of having clear objectives for management actions. At the same time, as range shifters are altering recipient communities, those communities themselves are responding to climate change; disentangling the causes and effects of these drivers will be a continuing challenge.

\section{Conclusions}

Although the impacts of range-shifting species can vary from minor to massive, considerations of species movements in the context of climate change has almost entirely focused on positive impacts ${ }^{7,28,86}$. As species shift to track a changing climate, we have a unique opportunity to facilitate advantageous, and discourage potentially problematic, movement of species in real time. However, both researchers and managers will likely need to adopt a more fluid and dynamic view of what constitutes a community, as differences in species' responses could result in communities with no current analogue $^{110}$. Communities are unlikely to shift as a whole, and partial shifts will disrupt species interactions and lead to trophic mismatches ${ }^{111}$. Rather than developing new strategies to evaluate the potential impacts of range-shifting species, we suggest leveraging invasion ecology theory and risk assessment tools (for example, EICAT) to quantify the magnitude of the potential impacts of range shifters and define specific conservation goals in response. This will allow us to maintain biodiversity and ecosystem functioning most effectively despite a rapidly changing climate.

Received: 21 May 2019; Accepted: 30 March 2020;

Published online: 30 April 2020

\section{References}

1. IPCC Climate Change 2014: Impacts, Adaptation, and Vulnerability (eds Field, C. B. et al.) (Cambridge Univ. Press, 2014)

2. Parmesan, C. \& Yohe, G. A globally coherent fingerprint of climate change impacts across natural systems. Nature 421, 37-42 (2003).

3. Sorte, C. J. B., Williams, S. L. \& Carlton, J. T. Marine range shifts and species introductions: comparative spread rates and community impacts. Glob. Ecol. Biogeogr. 19, 303-316 (2010).

4. Chen, I.-C., Hill, J. K., Ohlemüller, R., Roy, D. B. \& Thomas, C. D. Rapid range shifts of species associated with high levels of climate warming. Science 333, 1024-1026 (2011)

5. Pecl, G. T. et al. Biodiversity redistribution under climate change: impacts on ecosystems and human well-being. Science 355, eaai9214 (2017).

6. Lipton, D. et al. in Impacts, Risks, and Adaptation in the United States: Fourth National Climate Assessment, Volume II (eds Reidmiller, D. R. et al.) Ch. 7 (U. S. Global Change Research Program, 2018).

7. Hoegh-Guldberg, O. et al. Assisted colonization and rapid climate change. Science 321, 345-346 (2008).

8. Dawson, T. P., Jackson, S. T., House, J. I., Prentice, I. C. \& Mace, G. M. Beyond predictions: biodiversity conservation in a changing climate. Science 332, 53-58 (2011)

9. Hodgson, J. A., Thomas, C. D., Wintle, B. A. \& Moilanen, A. Climate change, connectivity and conservation decision making: back to basics. J. Appl. Ecol. 46, 964-969 (2009).

10. Nackley, L. L., West, A. G., Skowno, A. L. \& Bond, W. J. The nebulous ecology of native invasions. Trends Ecol. Evol. 32, 814-824 (2017).

11. McLachlan, J. S., Hellmann, J. J. \& Schwartz, M. W. Framework for debate of assisted migration in an era of climate change. Conserv. Biol. 21, 297-302 (2007).

12. Bonebrake, T. C. et al. Managing consequences of climate-driven species redistribution requires integration of ecology, conservation and social science. Biol. Rev. 93, 284-305 (2018).

13. Hargreaves, A. L., Samis, K. E. \& Eckert, C. G. Are species' range limits simply niche limits writ large? A review of transplant experiments beyond the range. Am. Nat. 183, 157-173 (2014).

14. Post, E. Ecology of Climate Change (Princeton Univ. Press, 2013).

15. Gilman, S. E., Urban, M. C., Tewksbury, J., Gilchrist, G. W. \& Holt, R. D. A framework for community interactions under climate change. Trends Ecol. Evol. 25, 325-331 (2010).

16. Wallingford, P. D. \& Sorte, C. J. B. Community regulation models as a framework for direct and indirect effects of climate change on species distributions. Ecosphere 10, e02790 (2019).

17. Harley, C. D. G. Climate change, keystone predation, and biodiversity loss. Science 334, 1124-1127 (2011).

18. Williamson, M. \& Fitter, A. The varying success of invaders. Ecology 77, 1661-1666 (1996).

19. Jeschke, J. M. \& Strayer, D. L. Invasion success of vertebrates in Europe and North America. Proc. Natl Acad. Sci. USA 102, 7198-7202 (2005).

20. Simberloff, D., Souza, L., Nuñez, M. A., Barrios-Garcia, M. N. \& Bunn, W. The natives are restless, but not often and mostly when disturbed. Ecology 93, 598-607 (2012).

21. Keane, R. M. \& Crawley, M. J. Exotic plant invasions and the enemy release hypothesis. Trends Ecol. Evol. 17, 164-170 (2002).

22. Pyšek, P. \& Richardson, D. M. in Biological Invasions (Ed. Nentwig, W.) 97-125 (Springer, 2008).

23. Catford, J. A., Jansson, R. \& Nilsson, C. Reducing redundancy in invasion ecology by integrating hypotheses into a single theoretical framework. Divers. Distrib. 15, 22-40 (2009).

24. Colautti, R. I., Grigorovich, I. A. \& MacIsaac, H. J. Propagule pressure: a null model for biological invasions. Biol. Invasions $\mathbf{8}$, 1023-1037 (2006). 
25. Leung, B. et al. TEASIng apart alien species risk assessments: a framework for best practices. Ecol. Lett. 15, 1475-1493 (2012).

26. Coutts, S. R., Helmstedt, K. J. \& Bennett, J. R. Invasion lags: the stories we tell ourselves and our inability to infer process from pattern. Divers. Distrib. 24, 244-251 (2018)

27. Lockwood, J. L., Cassey, P. \& Blackburn, T. The role of propagule pressure in explaining species invasions. Trends Ecol. Evol. 20, 223-228 (2005).

28. Ricciardi, A. \& Simberloff, D. Assisted colonization is not a viable conservation strategy. Trends Ecol. Evol. 24, 248-253 (2009).

29. Szűcs, M. et al. Rapid adaptive evolution in novel environments acts as an architect of population range expansion. Proc. Natl Acad. Sci. USA 114, 13501-13506 (2017)

30. Dale, V. H. et al. Climate change and forest disturbances. Bioscience 51, 723-734 (2001).

31. Thomas, C. D. Climate, climate change and range boundaries. Divers. Distrib. 16, 488-495 (2010).

32. Battisti, A. et al. Expansion of geographic range in the pine processionary moth caused by increased winter temperatures. Ecol. Appl. 15, 2084-2096 (2005).

33. Raffa, K. F., Powell, E. N. \& Townsend, P. A. Temperature-driven range expansion of an irruptive insect heightened by weakly coevolved plant defenses. Proc. Natl Acad. Sci. USA 110, 2193-2198 (2013).

34. Lesk, C., Coffel, E., D'Amato, A. W., Dodds, K. \& Horton, R. Threats to North American forests from southern pine beetle with warming winters. Nat. Clim. Change 7, 713-717 (2017).

35. Dukes, J. S. et al. Responses of insect pests, pathogens, and invasive plant species to climate change in the forests of northeastern North America: what can we predict? Can. J. For. Res. 39, 231-248 (2009).

36. Berg, E. E., David Henry, J., Fastie, C. L., De Volder, A. D. \& Matsuoka, S. M. Spruce beetle outbreaks on the Kenai Peninsula, Alaska, and Kluane National Park and Reserve, Yukon Territory: relationship to summer temperatures and regional differences in disturbance regimes. For. Ecol. Manage. 227, 219-232 (2006)

37. Weed, A. S., Ayres, M. P. \& Hicke, J. A. Consequences of climate change for biotic disturbances in North American forests. Ecol. Monogr. 83, 441-470 (2013).

38. Rice, S. K., Westerman, B. \& Federici, R. Impacts of the exotic, nitrogen-fixing black locust (Robinia pseudoacacia) on nitrogen-cycling in a pine-oak ecosystem. Plant Ecol. 174, 97-107 (2004).

39. McCarthy-Neumann, S. \& Ibáñez, I. Tree range expansion may be enhanced by escape from negative plant-soil feedbacks. Ecology 93, 2637-2649 (2012).

40. Iverson, L. R., Prasad, A. M., Matthews, S. N. \& Peters, M. Estimating potential habitat for 134 eastern US tree species under six climate scenarios. For. Ecol. Manage. 254, 390-406 (2008).

41. Ramos JE, Pecl GT, Moltschaniwskyj NA, Strugnell JM, León RI, S. J. Body size, growth and life span: Implications for the polewards range shift of Octopus tetricus in south-eastern Australia. PLOS ONE 9, E103480 (2014)

42. Hoving, H.-J. T. et al. Extreme plasticity in life-history strategy allows a migratory predator (jumbo squid) to cope with a changing climate. Glob. Chang. Biol. 19, 2089-2103 (2013).

43. Ramos, J. E. et al. Reproductive capacity of a marine species (Octopus tetricus) within a recent range extension area. Mar. Freshw. Res. 66, 999-1008 (2015)

44. Sunday, J. M. et al. Species traits and climate velocity explain geographic range shifts in an ocean-warming hotspot. Ecol. Lett. 18, 944-953 (2015).

45. Estrada, A., Morales-Castilla, I., Caplat, P. \& Early, R. Usefulness of species traits in predicting range shifts. Trends Ecol. Evol. 31, 190-203 (2016).

46. Ramos, J. E. et al. Population genetic signatures of a climate change driven marine range extension. Sci. Rep. 8, 9558 (2018).

47. Fridley, J. D. \& Sax, D. F. The imbalance of nature: revisiting a Darwinian framework for invasion biology. Glob. Ecol. Biogeogr. 23 1157-1166 (2014)

48. Cox, J. G. \& Lima, S. L. Naivete and an aquatic-terrestrial dichotomy in the effects of introduced predators. Trends Ecol. Evol. 21, 674-680 (2006).

49. HilleRisLambers, J., Harsch, M. A., Ettinger, A. K., Ford, K. R. \& Theobald, E. J. How will biotic interactions influence climate change-induced range shifts? Ann. NY Acad. Sci. 1297, 112-125 (2013).

50. Engelkes, T. et al. Successful range-expanding plants experience less above-ground and below-ground enemy impact. Nature 456, 946-948 (2008).

51. Katz, D. S. W. \& Ibáñez, I. Foliar damage beyond species distributions is partly explained by distance dependent interactions with natural enemies. Ecology 97, 2331-2341 (2016).

52. Frainer, A. et al. Climate-driven changes in functional biogeography of Arctic marine fish communities. Proc. Natl Acad. Sci. USA 114 12202-12207 (2017).

53. King, D. A., Bachelet, D. M. \& Symstad, A. J. Climate change and fire effects on a prairie-woodland ecotone: projecting species range shifts with a dynamic global vegetation model. Ecol. Evol. 3, 5076-5097 (2013).
54. Vergés, A. et al. Tropical rabbitfish and the deforestation of a warming temperate sea. J. Ecol. 102, 1518-1527 (2014).

55. Wernberg, T. et al. Climate-driven regime shift of a temperate marine ecosystem. Science 353, 169-172 (2016).

56. Vergés, A. et al. Long-term empirical evidence of ocean warming leading to tropicalization of fish communities, increased herbivory, and loss of kelp. Proc. Natl Acad. Sci. USA 113, 13791-13796 (2016).

57. Clavel, J., Julliard, R. \& Devictor, V. Worldwide decline of specialist species: toward a global functional homogenization? Front. Ecol. Environ. 9 222-228 (2011).

58. Gurevitch, J. \& Padilla, D. K. Are invasive species a major cause of extinctions? Trends Ecol. Evol. 19, 470-474 (2004).

59. Levine, J. M., Adler, P. B. \& Yelenik, S. G. A meta-analysis of biotic resistance to exotic plant invasions. Ecol. Lett. 7, 975-989 (2004).

60. Sakai, A. K. et al. The population biology of invasive species. Annu. Rev. Ecol. Syst. 32, 305-332 (2001).

61. Carey, M. P., Sanderson, B. L., Barnas, K. A. \& Olden, J. D. Native invaders - challenges for science, management, policy, and society. Front. Ecol. Environ. 10, 373-381 (2012).

62. Wood, C. M., Witham, J. W. \& Hunter, M. L. Climate-driven range shifts are stochastic processes at a local level: two flying squirrel species in Maine. Ecosphere 7, e01240 (2016).

63. Garroway, C. J. et al. Climate change induced hybridization in flying squirrels. Glob. Chang. Biol. 16, 113-121 (2010).

64. Krichbaum, K. \& Mahan, C. G. Steele, M. a, Turner, G. \& Hudson, P. J. The potential role of Strongyloides robustus on parasite-mediated competition between two species of flying squirrels (Glaucomys). J. Wildl. Dis. 46, 229-235 (2010).

65. Kennedy-Slaney, L., Bowman, J., Walpole, A. A. \& Pond, B. A. Northward bound: the distribution of white-tailed deer in Ontario under a changing climate. J. Wildl. Res. 45, 220-228 (2018).

66. Weiskopf, S. R., Ledee, O. E. \& Thompson, L. M. Climate change effects on deer and moose in the midwest. J. Wildl. Manage. 83, 769-781 (2019).

67. Tape, K. D., Gustine, D. D., Ruess, R. W., Adams, L. G. \& Clark, J. A. Range expansion of moose in arctic Alaska linked to warming and increased shrub habitat. PLoS ONE 11, e0152636 (2016).

68. Richardson, D. M. Ecology and Biogeography of Pinus (Cambridge Univ. Press, 1998).

69. Ling, S. D., Johnson, C. R., Ridgway, K., Hobday, A. J. \& Haddon, M. Climate-driven range extension of a sea urchin: inferring future trends by analysis of recent population dynamics. Glob. Chang. Biol. 15, 719-731 (2009).

70. Ling, S. D. et al. Global regime shift dynamics of catastrophic sea urchin overgrazing. Philos. Trans. R. Soc. B Biol. Sci. 370, 20130269 (2015).

71. Strain, E. \& Johnson, C. R. Competition between an invasive urchin and commercially fished abalone: effect on body condition, reproduction and survivorship. Mar. Ecol. Prog. Ser. 377, 169-182 (2009).

72. Bradley, B. A. et al. Disentangling the abundance-impact relationship for invasive species. Proc. Natl Acad. Sci. USA 116, 9919-9924 (2019).

73. Blackburn, T. M. et al. A unified classification of alien species based on the magnitude of their environmental impacts. PLoS Biol. 12, e1001850 (2014).

74. Greenwood, S. \& Jump, A. S. Consequences of treeline shifts for the diversity and function of high altitude ecosystems. Arctic Antarct. Alp. Res. 46, 829-840 (2014).

75. Lenoir, J. \& Svenning, J. C. Climate-related range shifts - a global multidimensional synthesis and new research directions. Ecography 38, 15-28 (2015).

76. Wagg, C., Bender, S. F., Widmer, F. \& van der Heijden, M. G. A. Soil biodiversity and soil community composition determine ecosystem multifunctionality. Proc. Natl Acad. Sci. USA 111, 5266-5270 (2014).

77. Angelo, C. L. \& Daehler, C. C. Upward expansion of fire-adapted grasses along a warming tropical elevation gradient. Ecography 36, 551-559 (2013).

78. Filbee-Dexter, K. Sea urchin barrens as alternative stable states of collapsed kelp ecosystems. Mar. Ecol. Prog. Ser. 495, 1-25 (2014).

79. Demopoulos, A. \& Smith, C. Invasive mangroves alter macrofaunal community structure and facilitate opportunistic exotics. Mar. Ecol. Prog. Ser. 404, 51-67 (2010)

80. Osland, M. J., Enwright, N., Day, R. H. \& Doyle, T. W. Winter climate change and coastal wetland foundation species: salt marshes vs. mangrove forests in the southeastern United States. Glob. Chang. Biol. 19, 1482-1494 (2013).

81. Bolser, R. C. \& Hay, M. E. Are tropical plants better defended? Palatability and defenses of temperate vs. tropical seaweeds. Ecology 77, 2269-2286 (1996).

82. Burkepile, D. E. \& Hay, M. E. Herbivore species richness and feeding complementarity affect community structure and function on a coral reef. Proc. Natl Acad. Sci. USA 105, 16201-16206 (2008).

83. Borer, E. T. et al. Global biogeography of autotroph chemistry: is insolation a driving force? Oikos 122, 1121-1130 (2013). 
84. Silliman, B. R. et al. Consumer fronts, global change, and runaway collapse in ecosystems. Annu. Rev. Ecol. Evol. Syst. 44, 503-538 (2013).

85. Campbell, A. H., Vergés, A. \& Steinberg, P. D. Demographic consequences of disease in a habitat-forming seaweed and impacts on interactions between natural enemies. Ecology 95, 142-152 (2014)

86. Vilà, M. et al. Ecological impacts of invasive alien plants: a meta-analysis of their effects on species, communities and ecosystems. Ecol. Lett. 14, 702-708 (2011).

87. Hawkins, C. L. et al. Framework and guidelines for implementing the proposed IUCN Environmental Impact Classification for Alien Taxa (EICAT). Divers. Distrib. 21, 1360-1363 (2015)

88. Scheffers, B. R. \& Pecl, G. Persecuting, protecting or ignoring biodiversity under climate change. Nat. Clim. Change 9, 581-586 (2019).

89. Stein, B. A. et al. Preparing for and managing change: climate adaptation for biodiversity and ecosystems. Front. Ecol. Environ. 11, 502-510 (2013).

90. Kreyling, J. et al. Assisted colonization: a question of focal units and recipient localities. Restor. Ecol. 19, 433-440 (2011).

91. Filbee-Dexter, K. et al. Ecological surprise: concept, synthesis, and social dimensions. Ecosphere 8, e02005 (2017).

92. Pimentel, D., Zuniga, R. \& Morrison, D. Update on the environmental and economic costs associated with alien-invasive species in the United States. Ecol. Econ. 52, 273-288 (2005).

93. Richardson, D. M. et al. Multidimensional evaluation of managed relocation. Proc. Natl Acad. Sci. USA 106, 9721-9724 (2009).

94. Vilà, M. et al. A review of impact assessment protocols of non-native plants. Biol. Invasions 21, 709-723 (2019).

95. Garibaldi, A. \& Turner, N. Cultural keystone species: implications for ecological conservation and restoration. Ecol. Soc. 9, 1 (2004).

96. Enquist, C. A. F. et al. Foundations of translational ecology. Front. Ecol. Environ. 15, 541-550 (2017).

97. Myers, N., Mittermeier, R. A., Mittermeier, C. G., da Fonseca, G. A. B. \& Kent, J. Biodiversity hotspots for conservation priorities. Nature 403, 853-858 (2000).

98. Ibáñez, I., Silander, J. A. Jr, Allen, J. M., Treanor, S. A. \& Wilson, A. Identifying hotspots for plant invasions and forecasting focal points of further spread. J. Appl. Ecol. 46, 1219-1228 (2009).

99. Allen, J. M. \& Bradley, B. A. Out of the weeds? Reduced plant invasion risk with climate change in the continental United States. Biol. Conserv. 203 306-312 (2016).

100. Pereyra, P. J. Rethinking the native range concept. Conserv. Biol. 34, 373-377 (2019).

101. Raymond, C. M. et al. Integrating local and scientific knowledge for environmental management. J. Environ. Manage. 91, 1766-1777 (2010).

102. Hutchins, L. W. The bases for temperature zonation in geographical distribution. Ecol. Monogr. 17, 325-335 (1947).

103. Araújo, M. B. \& Pearson, R. G. Equilibrium of species' distributions with climate. Ecography 28, 693-695 (2005).

104. Zarnetske, P. L., Skelly, D. K. \& Urban, M. C. Biotic multipliers of climate change. Science 336, 1516-1518 (2012).

105. Barnosky, A. D. et al. Has the Earth's sixth mass extinction already arrived? Nature 471, 51-57 (2011).

106. Blois, J. L., Zarnetske, P. L., Fitzpatrick, M. C. \& Finnegan, S. Climate change and the past, present, and future of biotic interactions. Science 341, 499-504 (2013).

107. Wilmers, C. C. \& Getz, W. M. Gray wolves as climate change buffers in Yellowstone. PLoS Biol. 3, e92 (2005).
108. Wilmers, C. C. \& Post, E. Predicting the influence of wolf-provided carrion on scavenger community dynamics under climate change scenarios. Glob. Chang. Biol. 12, 403-409 (2006).

109. Gedan, K. B., Silliman, B. R. \& Bertness, M. D. Centuries of human-driven change in salt marsh ecosystems. Ann. Rev. Mar. Sci 1, 117-141 (2009).

110. Williams, J. W. \& Jackson, S. T. Novel climates, no-analog communities, and ecological surprises. Front. Ecol. Environ. 5, 475-482 (2007).

111. Tylianakis, J. M., Laliberté, E., Nielsen, A. \& Bascompte, J. Conservation of species interaction networks. Biol. Conserv. 143, 2270-2279 (2010).

112. Gallina, S. \& Lopez Arevalo, H. Odocoileus virginianus (The IUCN Red List of Threatened Species, accessed 7 March 2020); https://doi.org/10.2305/ IUCN.UK.2016-2.RLTS.T42394A22162580.en

113. Hundertmark, K. Alces alces (The IUCN Red List of Threatened Species 2016, accessed 7 March 2020); https://doi.org/10.2305/IUCN.UK.2016-1. RLTS.T56003281A22157381.en

114. Gunn, A. Rangifer tarandus (The IUCN Red List of Threatened Species 2016, accessed 7 March 2020); https://doi.org/10.2305/IUCN.UK.2016-1. RLTS.T29742A22167140.en

\section{Acknowledgements}

This work was initiated at a working group led by C.J.B.S., B.A.B., A.E.B., and R.E. and was supported by the Albert and Elaine Borchard Foundation. We thank R. Whitlock for his insight during initial discussions, V. Pasquarella for her comments on an early draft, and C. Millar and J. McMullen who provided valuable feedback. Funding for this project was provided in the form of a University of Michigan catalyst grant to I.I., and from the National Institute of Food and Agriculture, U.S. Department of Agriculture, the Massachusetts Agricultural Experiment Station, the U.S. Geological Survey Northeast Climate Adaptation Science Center and the Department of Environmental Conservation under Project Number MAS00033 to B.A.B. Any use of trade, firm or product names is for descriptive purposes only and does not imply endorsement by the U.S. Government.

\section{Author contributions}

T.L.M., C.J.B.S. and P.D.W. conceptualized the idea for this Review independently. T.L.M. and P.D.W. proposed the project, led breakout sessions during the working group and managed the project throughout its development, including writing, reviewing and editing all manuscript versions. B.A.B. and C.J.B.S. provided invaluable feedback throughout the project and contributed though mentoring and supervision, as well as writing and in-depth review. B.A.B., B.B.L., T.L.M. and P.D.W. created figure visualizations. J.M.A., E.M.B., D.M.B., J.S.D., R.E., E.J.F., D.E.G., I.I., B.B.L. and M.V. contributed equally to writing and providing feedback.

\section{Competing interests}

The authors declare no competing interests.

\section{Additional information}

Correspondence should be addressed to T.L.M.

Peer review information Nature Climate Change thanks I-Ching Chen, Jorge E. Ramos and the other, anonymous, reviewer(s) for their contribution to the peer review of this work.

Reprints and permissions information is available at www.nature.com/reprints.

Publisher's note Springer Nature remains neutral with regard to jurisdictional claims in published maps and institutional affiliations.

(C) Springer Nature Limited 2020 